\title{
Locally Advanced Digestive System Neuroendocrine Carcinoma
}

National Cancer Institute

\section{Source}

National Cancer Institute. Locally Advanced Digestive System Neuroendocrine

Carcinoma. NCl Thesaurus. Code C155934.

A neuroendocrine carcinoma that arises from any part of the digestive system and has spread to nearby tissues or lymph nodes. 